\title{
The Healthy Health Care Workplace: a Competitive Advantage
}

\author{
Michael D. Parkinson ${ }^{1}$ \\ Published online: 31 August 2018 \\ (C) Springer Science+Business Media, LLC, part of Springer Nature 2018
}

\begin{abstract}
Purpose of Review This review provides an evidence-based approach to improve health, reduce excessive medical costs, and optimize productivity for health care employees and their families. What opportunities and challenges are unique or specific to health care organizations particularly as aligned with value and competitive advantage in achieving the Quadruple Aim?

Recent Findings An integrated approach to improving health and performance is essential. The strategy includes the employer "environment" (broadly defined), health and medical care behaviors, care delivery modalities, benefits alignment, and a supportive, total health and productivity integrated data analytic capability. Epigenetics and lifestyle medicine represent a promising direction in accelerating the prevention, treatment, and reversal of common chronic disease.

Summary An integrated health and productivity approach, emerging science, and practices can accelerate health care systems' goal to improve employee health and organizational competitiveness. Additional published examples of health care specific employer experience will further advance refinement of existing models and tailoring to the medical care setting.
\end{abstract}

Keywords Worksite wellness · Lifestyle medicine · Health promotion · Employer health and productivity · Well-being · Total worker health

\section{Introduction}

Health care systems and workplaces provide unique challenges and opportunities both to improve the health of employees and their families and to achieve the mission of delivering prevention-oriented, high quality, and affordable care to patients and communities. Declining US population health status in recent decades adversely impacts employees, their families, and employers who seek a healthy, high performing workforce in a competitive economy [1-3]. Workplace wellness programs, depending on their design, scope, and participation have produced variable improvement in health and medical costs $[4,5 \cdot \bullet]$. Concurrently, changes in health care financing, payment, delivery, and practice have accelerated driven by the Affordable Care Act and by appropriately demanding self-insured employers seeking lower costs and

This article is part of the Topical Collection on Public Health Policy

Michael D. Parkinson

Mdparkinson14@gmail.com

1 Principal, P3 Health ("Prevention, Performance, Productivity"), 5864 Aylesboro Avenue, Pittsburgh, PA 15217, USA better value. Despite these internal and external challenges, the core values of health care shared by leadership and colleagues viz. compassion, service, evidence, and excellence, can be leveraged to create healthier employees, achieve the organizational mission, and improve business performance. Healthy, engaged employees (and their families) produce better organizational outcomes - which in health care is high value medical care. Furthermore, the retention and recruitment of talented health care employees creates a competitive advantage in an era of increasing consolidation and shortage of personnel.

Over the past 30 years, employer best practices to improve employee health, productivity, and organizational performance have been developed. Integrated health and productivity models are transforming "silo-ed" thinking and practices in employer compensation, benefits, policies, environment, wellness programs, and medical care $[6,7,8,9 \bullet, 10 \bullet]$. Emphasis on health care value and the Triple Aim has led to payment reform tied not only to traditional quality measures but also to patient outcomes and satisfaction [11]. The expansion of Triple to the "Quadruple Aim," incorporating health care providers' sense of meaningful and impactful work to avoid "burnout," has recently emerged as a priority [12]. New accelerated approaches to prevent, treat, and actually 
reverse costly chronic disease are being deployed using lifestyle medicine competencies and delivery models. Expansion of worksite clinics and functions, architectural built design, health-enhancing environments, social psychology, new technologies, behavioral economics, and better integrated provider-patient models are being deployed to increase employee and family engagement and health.

\section{From "Wellness" and "Disease Care" to Integrated Health, Well-Being, Safety, Productivity, and Performance}

Where and how we live, learn, work, and play determine how long (number of years) and how well (quality of years) we survive and thrive [13]. Our homes, schools, workplaces, and communities create the environment which either supports or detracts from healthy behaviors which are the primary determinant of health, disease, disability, premature death, and total productivity costs. Employers have a key role to play not only in improving the health of their employees but also in extending their influence and "reach" to the employee's family, home, and community.

Edington's work over three decades with large, national employer cohorts convincingly demonstrated that health behaviors and risks predict health, care, and total productivity costs (employee performance, medical and mental health, absenteeism, turnover, disability, worker's compensation); and that lowering risk and improving behaviors similarly lowers total costs and improves business performance $[6,9 \bullet, 14-16]$. This predominantly health-focused model has been further informed by a broader study of employer determinants of work culture (well-being status, workplace practices, work factors) which are associated with higher employee productivity and business performance (individual well-being, individual performance and organizational performance) (Fig. 1) $[9,15,16]$.

The definition of a healthy workforce has evolved from a simplistic, dichotomous "healthy" vs "sick" to the essential, measurable characteristics of "healthy, productive, ready and resilient" which captures the more accurate wholistic, personal, and functional attributes integral to employer mission accomplishment and business success [8]. Reflecting this broader definition of a healthy employee, the National Institute of Occupational Safety and Health (NIOSH) created and supports the Total Worker Health ${ }^{\mathrm{TM}}$ national initiative to educate and assist employers to unite "health promotion" with "health protection" thinking, policies, and practices to promote worker health and improve organizational performance [10॰]. A recent multidisciplinary literature review commissioned by NIOSH informed the creation of a new framework for worker well-being. The major domains include workplace, physical environment, and safety climate; workplace policies and culture; health status; work evaluation and experience; and home, community, and society characteristics [17•].

If the goal is the creation of a healthy workforce, then, the challenges at a global level are two-fold. Approximately three quarters of costs in any employer population are due to chronic diseases which are caused predominantly by unhealthy behaviors and environments. Additionally, conservatively, an estimated third of total costs can be attributed to ineffective, inefficient, or poorly coordinated care.

Integrated strategies and models to promote a healthy workforce must address the core drivers of poor health, excessive medical costs, and lost productivity. The Employer Health and Productivity Roadmap ${ }^{\mathrm{TM}}$, presented at the inaugural national Total Worker Health ${ }^{\mathrm{TM}}$ conference, outlines six major elements shown to improve health, medical care, and productivity which can be delivered and measured by an employer and health care partner (Table 1) [18••].

\section{Optimize the Environment}

Employer culture and workplace environmental assessment tools have been developed to facilitate attitudinal, policy, and programmatic changes which can contribute to or detract from employee health, engagement, and performance [19, 20]. A recent comprehensive review of workplace culture of health indicated that built environment, policies and procedures, and communications were significantly correlated with health and or safety outcomes [21•].

\section{Increase Healthy Behaviors}

Periodic assessment of health behaviors and risks with a goal of $85 \%$ completion for employees and families creates an accurate picture of population health and improvement over time. Typical health risks include elevated body weight (BMI), stress, inadequate physical activity, elevated blood pressure, poor life satisfaction, smoking, safety belt non-usage, poor perception of health, illness days, existing medical conditions, elevated cholesterol, and excessive alcohol use [6]. Promoting and monitoring the delivery of US Preventive Services Task Force evidencebased "A" and "B" recommended clinical preventive services assures that screening tests, counseling interventions, and immunizations are delivered appropriately [22].

\section{Reduce Acute Care}

Increasing healthy behaviors reduces the incidence of acute illness and need for episodic care. Also, by creating readily accessible and lower-cost options for common acute conditions, employers and employees save both "direct" medical costs compared to emergency departments, urgent care centers or primary care physician offices and 


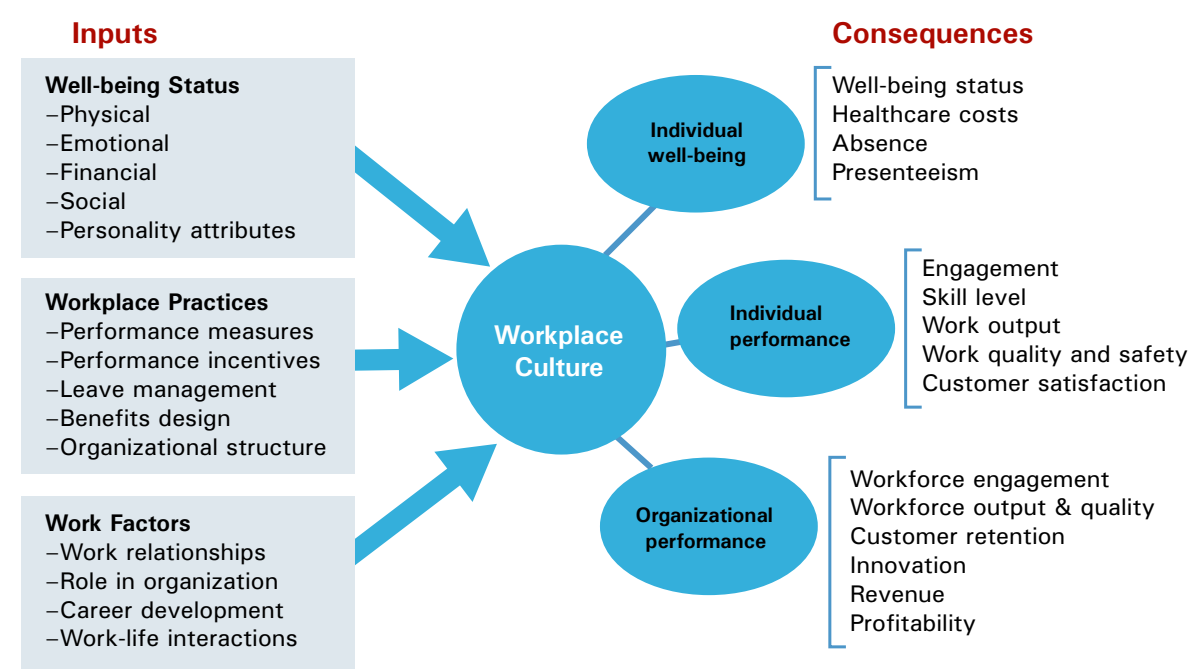

Fig. 1 A Conceptual Framework for Workforce Well-Being and Business Performance. (Adapted from: Sherman BW, Lynch WD. Am J Managed Care 2014;20:115-20; used with permission through Copyright Clearance Center, Inc.) [15]

"indirect costs" such as lost work time which can exceed medical care costs.

\section{Optimize Chronic Care}

Improving healthy behaviors, self-care, and chronic disease management for the $5 \%$ of employees and families which consistently drive $70 \%$ of total costs typically requires new care processes, technologies, office practice, or patient and family support.

\section{Reduce Excessive Surgery}

Optimizing lifestyle and medical management approaches to preference-sensitive surgeries and promoting the use of shared decision-aids has been shown to improve outcomes. The use of centers of excellence and reference-based pricing for high cost preference-sensitive surgeries is increasing [23, 24•].

\section{Speed Transitions from Care to Home to Work}

Providing whole-person support for injuries and illness which can be coordinated with employee assistance program resources, return-to-work, and disability management programs serves to return the employee to partial or full functionality benefitting both the employer and employer.

Health insurance benefit designs should differentially promote "high value" behaviors, services, and care and create financial incentives for prevention and engagement in care management (e.g., health coaching, online engagement, shared decision-making). In 2017, approximately $75 \%$ of large employers (greater than $1000 \mathrm{em}$ ployees) offered account-based consumer-directed plan designs (usually health savings accounts with partial employer funding) to encourage employee and family healthier behaviors, engagement, transparency, and taking an active role in care decisions [24-]. Integrated data bases employed by large employers usually with third party data aggregator and analysis partners which combine traditional health care data (medical claims, pharmacy, employee assistance program utilization) with safety, productivity, and performance data (job performance, accidents/injuries/errors, turnover, absences, disability, workers compensation, etc.) provides new insights and support opportunities for sub-populations of employees and family members who may benefit from predictive and early identification.

\section{The Competitive Health Care Business Advantage}

Relatively, few large health care organizations have published multi-year studies of the health and cost impact of their employee health programs $[25,26 \bullet]$. Deploying a systematic approach to improve employee health is good for both the "top line" (revenue) and "bottom line" (expenses) for businesses. Publicly traded companies who received the C Everett Koop Award for improving the health and well-being of their employees and dependents outperformed the S\&P 500 by $325 \%$ over a 14-year period [14]. What is the corollary business advantage for health care organizations whether "for profit" or "not-for-profit"?

Health care systems "business success" is increasingly being defined by their ability to achieve the Triple and now widely recognized, Quadruple Aim [11, 12]. Achieving better 
Table 1 Employer integrated health and productivity strategy: "Understand Your Health and Care, Improve Your Health and Care and Partner with Your Doctor"*

\begin{tabular}{|c|c|c|}
\hline Element & Metrics & Comment \\
\hline Optimize environment & $\begin{array}{l}\text { Comprehensive assessment of leadership, culture, built } \\
\text { environment; programs and health (absence management, } \\
\text { resources, communications); roles, responsibilities and } \\
\text { rewards; policy and compensation/benefits alignment }\end{array}$ & $\begin{array}{l}\text { Conduct at baseline and periodically to align with best } \\
\text { performance organizations }\end{array}$ \\
\hline \multirow[t]{2}{*}{ Improve health } & $\begin{array}{l}\text { Health behavior and risk factor assessment } \\
\text { "Low," "medium," and "high-risk" sub-groups }\end{array}$ & $\begin{array}{l}\text { Conduct at baseline and periodically with } 85 \% \text { target } \\
\text { completion for accurate assessment and prediction }\end{array}$ \\
\hline & "Champions" with lowest risk/healthiest behaviors & $\begin{array}{l}\text { Maintain lower risk and shift higher to lower risk. Increase } \\
\text { number and \% champions. }\end{array}$ \\
\hline Reduce acute care & $\begin{array}{l}\text { Determine ER, urgent care and primary care visits which } \\
\text { could be delivered at onsite clinic or using telehealth }\end{array}$ & $\begin{array}{l}\text { Reduce demand for acute care with healthy behaviors and } \\
\text { deliver at most convenient, lower cost site }\end{array}$ \\
\hline Optimize chronic care & $\begin{array}{l}\text { Condition prevalence over time } \\
\text { Proportion of chronic disease patients with competent } \\
\text { self-care management and healthy behaviors }\end{array}$ & $\begin{array}{l}\text { Completion of online, telephonic or in-person health } \\
\text { coaching programs }\end{array}$ \\
\hline $\begin{array}{l}\text { Reduce excessive } \\
\text { surgery }\end{array}$ & $\begin{array}{l}\text { Shared decision-making aid use before preference-sensitive } \\
\text { surgeries }\end{array}$ & $\begin{array}{l}\text { Emphasis on orthopedic, cardiac procedures and other } \\
\text { preference-sensitive conditions }\end{array}$ \\
\hline $\begin{array}{l}\text { Speed transitions } \\
\text { care-home-work }\end{array}$ & $\begin{array}{l}\text { Monitor return to work time for common injuries and } \\
\text { surgeries }\end{array}$ & Include absence, disability and workers compensation \\
\hline
\end{tabular}

*Health insurance benefit design promoting engagement using either an incentivized health management program or incentivized, account-based consumer-directed health plan

(Adapted from: Parkinson MD. Jour Occup Envir Med 2013:55(Supp); S46-51) [17••]

patient outcomes through improved safety, error reduction, and technical quality; improving the experience of care by empathetically and compassionately serving patients and families and lowering the per capita cost of care can only be achieved through a healthy, engaged, and resilient healthcare workforce.

Health care individual level business performance metrics include patient complaints, occupational injury incidence and clinical error incidence. Typical aggregate business level performance measures include patient satisfaction, quality measure compliance, complication rates, and in-hospital mortality [15]. Health, safety and business performance alignment will become more critical over time as financing and delivery models move from "volume to value" with concomitant economic and market share rewards and penalties.

The challenges and strategies essential for today's health care leaders to improve "population health" cost-effectively closely parallel those required for organization's employees and families [27]. These include understanding the population and using predictive analytics; redesigning primary care; forming new partnerships and using telemedicine and technologies; prioritizing health promotion and addressing social determinants of health; codesigning and coproducing care with patients; and engaging and empowering frontline staff and learners in care transformation. Better employee health is not only aligned with the business goals of health care systems but also provides a real-world example of how to accelerate and improve the care delivered to patients and the community. By "walking the talk" of deploying a metric-defined strategy and demonstrating year-over-year progress toward creating a healthier workforce with lower health and productivity costs, health care systems can work closely with employers and payers to gain market share and meet mutual business objectives.

\section{Growing Challenge of Health Care Professional Burnout}

Professional well-being is now recognized as essential to provider and staff health, high-quality patient care and overall health system performance [28-31]. "Burnout" is increasingly viewed as a health care-specific occupational hazard manifest by low satisfaction, stress, depression, anxiety, suicide risk, compassion fatigue and loss of empathy; poor work performance, and high turnover rates. Burnout leads to lower levels of staff engagement and affects all aspects of patient carequality, safety, and outcomes. Lower customer (patient) experience, decreased productivity, and increased risk of workplace accidents and safety events all compromise individual outcomes, staff satisfaction, and organizational goals. The IHI Framework for Improving Joy in Work defines nine critical components which reinforce the major constructs of an integrated worksite approach to individual and organizational health and performance. The nine components can and should also be evaluated in the baseline environmental assessment ("optimize the environment"): meaning and purpose, choice 
and autonomy, recognition and rewards, participative management, camaraderie and teamwork, daily improvement, wellness and resilience, real-time measurement, and physical and psychological safety.

Furthermore, if physicians and the medical care team are to serve as healthy role models for their colleagues and patients, the linkage between their professional fulfillment and the three major contributing elements (culture of wellness, personal resilience and efficiency of practice) need to be addressed [32, 33].

\section{New Science and Practice: Epigenetics and Lifestyle Medicine}

Ecologic and cross-cultural studies of healthy lifestyle and environments, both internationally and in US populations, have consistently demonstrated the longest lives with most vitality [34-36, 37••]. Yet while the impact of healthy behaviors on life expectancy has been well-established, the shortening life expectancy of Americans has renewed the urgency of improving lifestyle and at any age [38]. This growing awareness, coupled with the rapidly evolving scientific understanding of epigenetics, represents a new front in the prevention, treatment, and even reversal of common diseases. The definition of lifestyle medicine competencies and the creation of curriculum and certification pathways have further moved the practice of medicine toward addressing "root causes" of disease, morbidity, premature disability, and costs [39, 40•].

Rapid protein expression by our genes in response to environmental and behavioral change impacts the microbiome, oxidative stress, and systemic inflammation providing a new "root cause" approach for employers and providers to address poor health and rising rates of preventable and impactable chronic diseases [41••]. Small scale studies and controlled trials at the community or employer level have consistently demonstrated biometric and clinical improvements [42, 43]. Based on large scale cohort studies and clinical interventions shown to prevent, treat, and even reverse cardiovascular disease, early stage cancers and other conditions, some leading employers are moving to provide intensive lifestyle disease reversal programs to employees and family members, particularly those with multiple chronic diseases and medications [44, 45].

Established medical specialty societies are further calling for the medical community to emphasize plant-based eating as the healthiest route to longer life with minimal preventable disease [46, 47]. Health care systems can offer training in lifestyle medicine to health care providers and in turn, establish clinical offerings which produce employee and family health benefits as well. Re-orienting facilities to emphasize plant-based eating for all food services, providing onsite physical activity opportunities and building mindfulness competency and rest areas to address stress and resiliency represent the next generation healthcare workplace.

\section{Emerging Trends}

Employers are incorporating new scientific, clinical, and economic practices to initiate and sustain healthy behaviors and reinforcing environments. In the process, leading large employers and new venture-capital supported delivery models are pushing health care systems to become more transformative in how they address the determinants of disease and ineffective, costly medical care practices.

Large employers (typically greater than 1000 employees) are offering onsite or near-site clinics which provide convenience, lower cost, and productivity-savings [24•, 48]. Traditionally, limited to occupational health and acute care, worksite clinics increasingly include prevention, lifestyle improvement, disease management, case management, injury prevention/safety, care decision, and transparency support and telehealth services.

Employers are emphasizing comprehensive employee and family "wellbeing" which is defined as physical, emotional, and financial health. Direct assessment of employee engagement and patient activation using new validated tools is being utilized to create a baseline for improving commitment to health, navigation of the health system, and shared decisionmaking which in turn improves well-being through greater health, vitality, and better health care choices and spending $[49,50]$.

Better understanding of the mind-body continuum including the neuro-humoral science of "happiness" and the production of dopamine/endorphins by multiple stimuli have improved understanding of the chemistry and pathways to enhanced well-being. The power of social connection which underlies the phenomena of connection and contagion and of intrinsic motivators which can be very personal and strongest (purpose, passion, mission) are also being described and deployed [7, 51]. Assisting employees to become competent in mind-body stress reduction and cognitive performance improving techniques such as mindfulness, medication, yoga, and other modalities is increasingly common.

Built environments which design-in healthy architectural and human support systems which naturally promote productivity as well as the deployment of choice architecture which makes the "right thing to do the easy thing to do" is becoming more mainstream in creating and sustaining a culture of health. Re-connecting individuals and home, school, worksite, and health care settings to the natural outdoor environment with an emphasis on sustainability has been shown to improve both public health and human functioning [52-54].

Behavioral economics and thoughtful alignment and application of financial and psychological incentives have increasingly informed the design and deployment of comprehensive 
health management programs. Increasingly employers are deploying "opt-out" rather than "opt-in" incentive structures, leveraging peer support, and creating social rewards and recognition rather than dollars to improve health $[55,56]$.

Personal biomeasurement with real- or near-time feedback using wearable technologies tethered to social media support for ongoing behavior change and optimal self-care is promising and appeals to an increasingly "wired" generation. However, employers are recognizing that digital health engagement is yet in its formative stage to produce desired health and cost outcomes [57].

Physicians prescribing coaching or web-based technologies can be integrated in electronic medical records for improving health, chronic disease self-care, and shared decisionmaking. By leveraging the trusted patient-physician relationship and by using people, process and technology, provider groups can increase patient engagement, improve health outcomes, and increase provider satisfaction [58].

\section{Conclusion}

Health care organizations are both ideally suited and uniquely challenged to implement a best practice workplace health, safety, and productivity strategy to improve employee and family health; and in turn, create a competitive advantage by growing successful health care business, market share and examples for employers and the community-at-large. The challenge begins with understanding the goal viz. creating a healthy, productive, ready, and resilient workforce (including families) by addressing the majority of disease, excessive medical costs and lost productivity rooted in unhealthy behaviors and unsupportive environments, ineffective care and uncoordinated policies, practices, and benefits. Creating a supportive broadly-defined environment with aligned vision and incentives which makes the "right" choice the expected, "easy" one is formidable but achievable. With a clear view of the goal and the challenges, health care leaders can create a common vision and deploy a measurable strategy with aligned policies, incentives, practices, and proven innovations to create a healthier, high performing workforce; embrace the Quadruple Aim; and achieve organizational success.

\section{Compliance with Ethical Standards}

Conflict of Interest Michael D. Parkinson reports the following disclosures: UPMC Health Plan and WorkPartners, Senior Medical Director, Health and Productivity.

Human and Animal Rights and Informed Consent This article does not contain any studies with human or animal subjects performed by any of the authors.

\section{References}

Papers of particular interest, published recently, have been highlighted as:

- Of importance

- Of major importance

1. Centers for Disease Control. Obesity/weight status maps from behavioral risk factor surveillance system data. https://nccd.cdc.gov/ dnpao_dtm/rdPage.aspx? rdReport=DNPAO_DTM. ExploreByTopic \&islClass $=$ OWS \&is1Topic $=\mathrm{OWS} 1 \& \mathrm{go}=\mathrm{GO}$ Accessed June 20, 2018.

2. Lundeen EA, Park S, Pan L, et al. Obesity prevalence among adults living in metropolitan and nonmetropolitan counties-United States, 2016. MMWR Morb Mortal Wkly Rep. 2018 Jun 15;67(23):653-658. https://doi.org/10.15585/mmwr.mm6723al

3. Pronk N. An optimal lifestyle metric: four simple behaviors that affect health, cost and productivity. ACSM Health and Fitness Journal. 2012;16(3):39-43.

4. Baicker K, Cutler D, Song Z. Workplace wellness programs can generate savings. Health Aff. 2010;29:304-11.

5. Mattke S, Kapinos KA, Caloyeras J et al. Workplace wellness programs: services offered, participation, and incentives. RAND Health Quarterly, 2015; 5(2):7. Comprehensive review of health and disease management programs and outcomes.

6. Edington DW. Zero trends: health as a serious economic strategy. Ann Arbor: University of Michigan Health Management Research Center; 2009.

7. Edington DW, Pitts JS. Shared values, shared results: positive organizational health as a win-win philosophy. ISBN 978-0-69256153-9 Middletown, DE; 2016.

8. Institute of Medicine. Integrating employee health: a model program for NASA. Washington, DC: National Academy of Sciences; 2005. ISBN 0-309-09623-5 (pbk.)—ISBN 0-30954955-8 (pdf) 1.

9. Lynch W, Gardner H. Who survives? How benefit costs are killing your company. Health as Human Capital Foundation, Cheyenne WY 2011. Summary of employer-controlled, non-health factors influencing medical and total productivity costs.

10. National Institute for Occupational Safety and Health (NIOSH). Total Worker Health ${ }^{\mathrm{TM}}$ https://www.cdc.gov/niosh/ twh/accessed 20 Oct 2017. National framework for integrating employer health promotion and health protection vs traditional approach.

11. Berwick DM, Nolan TW, Whittington J. The triple aim: care, health, and cost. Health Affairs 2008 May/June; 27(3):759-769.

12. Sikka R, Morath JM, Leape L. The Quadruple Aim: care, health, cost and meaning in work. BMJ Qual Saf. 2015;24:608-10.

13. Robert Wood Johnson Foundation 2009. Beyond health care: new directions to a healthier America. https:/www.rwjf.org/content/ dam/farm/reports/reports/2009/rwjf40483nson. Accessed 27 Oct 2017.

14. Goetzel RZ, Fabius R, Fabius D, Roemer EC, Thornton N, Kelly $\mathrm{RK}$, et al. The stock performance of C. Everett Koop award winners compared with the Standard \& Poor's 500 Index. J Occup Environ Med. 2016;58(1):9-15.

15. Sherman BW, Lynch WD. Connecting the dots: examining the link between workforce health and business performance. Am J Managed Care. 2014;20:115-20.

16. Loeppke RR, Hohn T, Baase C, Bunn WB, Burton WN, Eisenberg $\mathrm{BS}$, et al. Integrating health and safely in the workplace: how closely aligning health and safety strategies can yield measurable benefits. J Occup Envir Med. 2015;57(5):585-97. 
17. Chari R, Chang CC, Sauter SL, et al. Expanding the paradigm of occupational safety and health. A new framework for worker wellbeing. J Occup Envir Med 2018;60:589-593. Expands and codifies generic major domains, subdomains and constructs which can be measured to understand and improve total worker health.

18.• Parkinson MD. Employer health and productivity roadmap ${ }^{\mathrm{TM}}$ strategy. Jour Occup Envir Med 2013:55(Supp); S46-51. Evidencebased strategy with core elements and metrics to address major drivers of poor health, excessive medical costs and lost productivity.

19. Centers for Disease Control and Prevention. The CDC worksite health scorecard: an assessment tool for employers to prevent heart disease, stroke and related health conditions. Atlanta: US Department of Health and Human Services; 2014.

20. Health Enhancement Research Organization (HERO). The HERO health and well-being best practices scorecard in collaboration with Mercer (copyright). https://hero-health.org/hero-scorecard/ accessed June 20, 2018

21. Flynn JP, Gascon G, Doyle S, et al. Supporting a culture of health in the workplace: a review of evidence-based elements. Am J public health 2018; DOI: 1177/0890117118761887. Comprehensive analyses of employer culture of health determinants from using strict study selection criteria by national expert body.

22. US Department of Health and Human Services Agency for Healthcare Research and Quality 2014. US Preventive Services Task Force Guide to Clinical Preventive Services. https://www. ahrq.gov/sites/default/files/wysiwyg/professionals/cliniciansproviders/guidelines-recommendations/guide/cpsguide.pdf. Accessed Oct 27, 2017.

23. Zhang H, Cowling DW, Facer M. Comparing the effects of reference pricing and centers-of-excellence approaches to value-based benefit design. Health Aff (Millwood) 2017;36(12):2094-2101. doi: https://doi.org/10.1377/hlthaff.2017.056323.

24. Willis Towers Watson. High performance insights - best practices in healthcare. 2017 22nd annual Willis Towers Watson best practices in health care employer survey. https://www. willistowerswatson.com/-/media/WTW/PDF/Insights/2018/01/ 2017-best-practices-in-health-care-employer-survey-print-wtw.pdf (accessed Jun 17, 2018). Most current comprehensive survey of large employer best practices including healthcare organizations with greater than 1,000 employees.

25. Byrne DW, Goetzel RZ, McGown PW, et al. Seven-year trends in employee health habits from a comprehensive workplace health promotion program at Vanderbilt University. J Occup Environ Med. 2013;53(12):1372-81.

26. Parkinson MD, Peele PB, Keyser DJ et al. UPMC MyHealth: managing the health and costs of U.S. healthcare workers. Am Jour Prev Med 2014;47(4):403-410. Largest and longest continuing healthcare employee propensity-matched cohort using incentivized program studied for health, care and costs.

27. Shaikh U, Roth A. Five organizational strategies to deliver high value health care. Am Jour Med Qual. 2017;32(5):566-8.

28. Shanafelt TD, Hasan O, Dyrbye LN, et al. Changes in burnout and satisfaction with work-life balance in physicians and the general US working population between 2011 and 2014. Mayo Clin Proc. 901(12):1600-13. https://doi.org/10.1016/jmayocp.2015.08.023.

29. Lucian Leape Institute. Through the eyes of the workforce: creating joy, meaning, and safer health care. Boston: National Patient Safety Foundation; 2013.

30. Tawfik DS, Profit J, Morgenthaler TI, Satele DV, Sinsky CA, Dyrbye LN, et al. Physician burnout, well-being, and work unit safety grades in relationship to reported medical errors. Mayo Clin Proc. 2018; https://doi.org/10.1016/j.mayocp.2018.05.014.

31. Perlo J, Balik B, Swensen S, et al. IHI framework for improving joy in work, IHI white paper. Cambridge, MA: Institute for Healthcare
Improvement 2017. (Available at www.ihi.org) accessed June 20, 2018.

32. Lesser LI, Cohen DA, Brook RH. Changing eating habits for the medical profession. JAMA. 2012;308:983-4.

33. Stanford Medicine Well MD Program. https://wellmd.stanford.edu/ center1.html accessed June 20, 2018.

34. Willcox BJ, Willcox C, Suzuki M. The Okinawa Program: How the world's longest-lived people achieve everlasting health — and how you can too. Clarkson Potter Publishers, New York, NY, 2001.

35. Buettner D The Blue Zones: lessons for living longer from the people who've lived the longest. ISBN13: 9781426202742, 2008.

36. Willett WC et al 2017. Health professionals follow up study (physicians, nurses, health professionals) https://sitessphharvardedu/ hpfs/accessed June 20, 2017.

37.• Greger, M. How not to die. Flatiron Books, NY, NY; 2015. Most current, comprehensive and referenced text relating nutrition and lifestyle to US leading causes of death.

38. Li Y, Pan A, Wang DD, et al. Impact of healthy lifestyle factors on life expectancies in the US population. Circulation. 2018;137 https://doi.org/10.1161/CIRCULATIONAHA.117.032047.

39. Lianov L, Johnson M. Physician competencies for prescribing lifestyle medicine. JAMA. 2010;304:202-3.

40. American College of Preventive Medicine, American College of Lifestyle Medicine. Lifestyle medicine core competencies program. https://www.acpm.org/general/custom.asp?page=lmprogram. (Accessed June 20, 2018). Thirty-hour continuing medical and health professional education on core competencies in lifestyle medicine leading to certification eligibility.

41.• Bodai BI, Nakata TE, Wong WT, et al. The Permanente Lifestyle medicine: a brief review of its impact on health and survival Journal/Perm J 2018;22:17-025.. Journal/Perm J 2018;22:17-025. $\mathrm{http} / / / w w w . t h e p e r m a n e n t e j o u r n a l . o r g /$ issues/2018/6536-lifestylemedicine-a-brief-review-of-its-dramatic-impact-on-health-andsurvival.html. Accessed June 20, 2018. Multiple physician specialist review of evidence for lifestyle treatment and etiologic mechanisms in reversal of common diseases.

42. Mishra S, Xu J, Gonzales J, et al. A multicenter randomized controlled trial of a plant-based nutrition program to reduce body weight and cardiovascular risk in the corporate setting: the GEICO study. Eur J Clin Nutrition. 2013;67:1-7. https://doi.org/ 10.1038/ejcn.2013.92.

43. Wright N, Wilson L, Smith M, Duncan B, McHugh P. The BROAD study: a randomized controlled trial using a whole food plant-based diet in the community for obesity, ischaemic heart disease or diabetes. Nutr Diabetes. 2017;7(3):e256. https://doi.org/10.1038/nutd. 2017.3.

44. Forrester DD. Leading innovations in prevention and cure. Phys Exec. 2013;5:60-6.

45. Cummins Corporation. http://www.cumminslivewell.com/ accessed June 20, 2018.

46. Satija A, Bhupathiraju SN, Spiegelman D, Chiuve SE, Manson JAE, Willett W, et al. Health and unhealthful plant-based diets and the risk of coronary heart disease in US adults. J Am Coll Cardiol. 2017;70:411-22.

47. Williams KA, Patel H. Healthy plant-based diet: what does it really mean? J Am Coll Cardiol. 2017;70:423-4.

48. Wells Fargo. Wells Fargo insurance white paper: the role of employer-based onsite clinics; total population management strategy 2015. https://wfis.usi.com/insights/whitepapers/Documents/ Employer-based-onsite-clinics.pdf. Accessed June 20, 2018.

49. Hibbard JH, Greene J, Sacks RM, Overton V, Parrotta C. Improving population health management strategies: identifying patients who are more likely to be users of avoidable costly care and those more likely to develop a new chronic disease. Health Serv Res. 2017 Aug;52(4):1297-309. https://doi.org/10.1111/1475-6773.12545. 
50. Duke CC, Lynch WD, Smith B, Winstanley J. Validity of a new patient engagement measure: the Altarum consumer engagement (ACE) measure. Patient. 2015;8(6):559-68.

51. Christakis NA, Fowler JA. Connected: The Surprising Power of Our Social Networks and How They Shape Our Lives. Little, Brown and Company, 2009.

52. Jackson RJ, Sinclair S. Designing Healthy Communities. Josseybass, ISBN 978111803366. San Francisco, CA 2012.

53. Jennings VL, Larson CK, Larson LR. Ecosystem services and preventive medicine: a natural connection. Am Jour Prev Med. 2016;50(5):642-5.

54. Center for Health Design. http://healthierhospitals.org (accessed June 20, 2018).

55. Volpp KG, Asch DA, Galvin R, et al. Redesigning employee health incentives - lessons from behavioral economics. N Engl J Med. 2011;365:388-90.
56. Asch DA, Volpp KG. Use behavioral economics to achieve wellness goals. Harvard Business Review December 01, 2014.

57. O'Connor S, Hanlon P, O'Donnell CA, et al. Understanding factors affecting patient and public engagement and recruitment to digital health interventions: a systematic review of qualitative studies. BMC Med Inform Decis Mak 2016;16:120. Published online 2016 Sep 15. doi: https://doi.org/10.1186/s12911-016-0359-3

58. Maners RJ, Bakow E, Parkinson MD et al. UPMC prescription for wellness: a quality improvement case study for supporting patient engagement and health behavior change. Am Jour Med Qual 2017: https://doi.org/10.1177/1062860617741670 accessed 23 Nov 2017. 